\title{
The role of gasotransmitters in movement of stomata: mechanisms of action and importance for plant immunity
}

\author{
S. GAHIR, P. BHARATH, and A.S. RAGHAVENDRA* \\ Department of Plant Sciences, School of Life Sciences, University of Hyderabad, Hyderabad 500046, India
}

\begin{abstract}
Stomatal guard cells are specialized epidermal cells regulating gas exchange. The ability to open or close in response to external and internal cues makes stomata a dynamic and fascinating system. Stomatal closure upon infection ensures restriction of pathogen entry into the plant and forms an essential component of innate immunity. The opening or closure of stomata is dependent on the turgidity or flaccidity of guard cells, respectively, facilitated by several signaling components, including reactive oxygen species, nitric oxide (NO) and $\mathrm{Ca}^{2+}$. Among these, $\mathrm{NO}$ is the most extensively studied gasotransmitter. Its pivotal role in stomatal closure by modulating various downstream components as well as regulation of crucial proteins by post-translational modifications makes NO an essential factor. Two more gasotransmitters, carbon monoxide and hydrogen sulfide, also trigger stomatal closure. Other gaseous molecules, like ethylene, methane, sulfur dioxide, ozone, and $\mathrm{CO}_{2}$, can modulate stomatal closure, but they are not considered strictly as gasotransmitters due to specific criteria. We review the signaling events in guard cells triggered by these gasotransmitters leading to stomatal closure. We point out the dual role of NO to promote stomatal closure and stomatal opening. Both $\mathrm{NO}_{\text {and }} \mathrm{H}_{2} \mathrm{~S}$ help in reinforcing the innate immunity against pathogen attack. Although there is extensive information on the mechanism of NO action on stomata, the enzymatic source of NO or CO is still ambiguous. Similarly, research is warranted to establish the relative importance of and interactions among the three main gasotransmitters. Further studies on gasotransmitters would answer the ambiguity about their functions and confirm if they can act independently.
\end{abstract}

Additional key words: carbon monoxide, guard cells, hydrogen sulfide, nitric oxide, signaling compounds.

\section{Introduction}

Given their immobile nature, plants have to adapt against a broad spectrum of stresses. Stomata play a crucial role in such adaptations (Hetherington and Woodward 2003). Stomata, the microscopic pores on the leaf surface, regulate not only $\mathrm{CO}_{2}$ exchange and transpiration, but also restrict the entry of microbes into leaves. As a result, stomata are considered as essential components of plant innate immunity response, as their closure physically restricts further entry of pathogens (Melotto et al. 2017). The closing or opening of stomata is dependent on the pressure potential within guard cells (Underwood et al.
2007). Stomatal guard cells can sense and respond to environmental factors, plant hormones, and microbial elicitors (Alcázar et al. 2006, Acharya et al. 2009).

The process of stomatal closure involves an array of signalling components: phosphatases, kinases, and other secondary messengers, all of which lead to modulation of ion channels, and loss of cations/anions, leading to decrease in pressure potential in guard cells and stomatal closure (Munemasa et al. 2015, Agurla and Raghavendra 2016, Saito and Uozumi 2019). These events converge and diverge at specific points while keeping up a dynamic cross-talk among them. The major signalling components in guard cells are reactive oxygen species (ROS), nitric

Submitted 4 April 2020, last revision 6 May 2020, accepted 11 May 2020.

Abbreviations: ABA - abscisic acid, cADPR - cyclic ADP ribose, cGMP - cyclic guanosine monophosphate, ET - ethylene, HO heme oxygenase, $\mathrm{IP}_{3}$ - inositol 1,4,5-triphosphate, MeJA - methyl jasmonate, OST1 - open stomata1, PA - phosphatidic acid, PLC phospholipase C, PLD - phospholipase D, PTM - post-translational modification(s), ROS - reactive oxygen species, SA - salicylic acid, SLAC - slow anion channel.

Acknowledgments: Our work on stomatal guard cells was supported by grants (to ASR) of the JC Bose National Fellowship (No. SR/S2/ JCB-06/2006) from the Science and Engineering Research Board and Council of Scientific and Industrial Research [No. 38 (1404)/15/ EMR-II], both from New Delhi. SG was a recipient of a Junior Research Fellowship from the University Grant Commission. PB was supported partially by a BBL fellowship (UoH). The first two authors contributed equally to this review.

* Corresponding author; e-mail: as_raghavendra@yahoo.com 


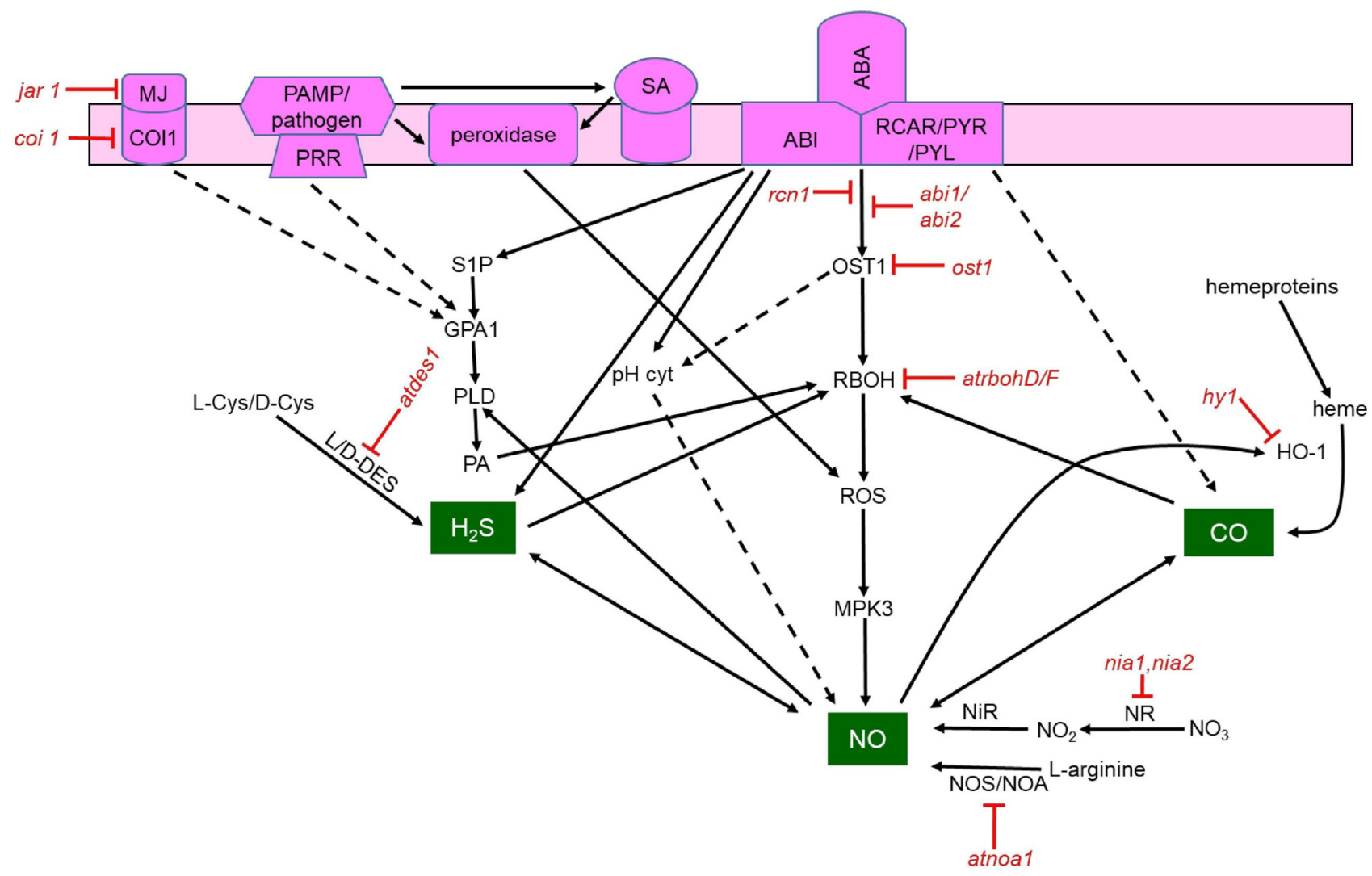

Fig. 1. A schematic representation of the events in guard cells leading to the production of the three typical gasotransmitters: nitric oxide (NO), carbon monoxide $(\mathrm{CO})$, and hydrogen sulfide $\left(\mathrm{H}_{2} \mathrm{~S}\right)$. The guard cells sense hormones/elicitors by receptors and respond by activation of NADPH oxidase (RBOH) or peroxidase. As a result, the levels of reactive oxygen species (ROS) rise. A significant source of ROS in the guard cell is NADPH oxidase, modulated by open stomata 1 (OST1) kinase and phosphatidic acid (PA) produced from either phospholipase C or D (PLC/PLD). The ROS production can be facilitated also by peroxidase. The rise in ROS invariably increases the content of $\mathrm{NO}$, a vital gasotransmitter, in guard cells. The source of $\mathrm{NO}$ in plant cells is debatable if produced from nitrate or L-arginine through nitrate/nitrite reductase (NR/NiR) or a nitric oxide synthase-like enzyme (NOS/NOA). A rise in cytosolic pH can also stimulate the content of ROS as well as NO, but the exact mechanism is not clear. The second gasotransmitter, CO, often considered as a co-modulator with NO, can stimulate NADPH oxidase, increase in ROS as well as NO. When present, NO up-regulates the enzyme heme oxygenase (HO) to enhance $\mathrm{CO}$ production in the guard cell. The third gasotransmitter, $\mathrm{H}_{2} \mathrm{~S}$, is produced from L/D-cysteine by the action of enzyme L/D-cysteine desulfhydrase (L/D-DES). The production of three gasotransmitters appears to be quite interactive and mutually stimulative. Similarly, the rise in ROS content stimulates NO-production and vice versa. Red arrows/letters indicate the conclusions validated by Arabidopsis mutants (details listed in Table 1 Suppl). Other abbreviations: ABI - abscisic acid insensitive; COI - coronatine insensitive; GPA - G-protein alpha subunit; HO - heme oxygenase; L/D-DES - L/D-cysteine desulfhydrase; MJ methyl jasmonate; MPK - mitogen activated protein kinase; NiR - nitrite reductase; NO - nitric oxide; NO2 - nitrite; NO3 - nitrate; NOA - nitric oxide associated ; NOS - nitric oxide synthase; OST - open stomata; PA - phosphatidic acid; PAMP - pathogen associated molecular pattern(s); PLC - phospholipase C; PLD - phospholipase D; PRR - pattern recognition receptor(s); RBOH - respiratory burst oxidase homolog; SA - salicylic acid; S1P - sphingosine-1-phosphate.

oxide (NO), cytosolic $\mathrm{pH}$, and calcium $\left(\mathrm{Ca}^{2+}\right)$, which modulate ion channels (Raghavendra and Murata 2017, Agurla et al. 2018a). The rise in NO in guard cells is an essential event during stomatal closure (Fig. 1). Several compounds induce NO production: plant hormones [abscisic acid (ABA), ethylene (ET), and methyl jasmonate (MeJA)], elicitors [salicylic acid (SA), cryptogein, harpin, flagellin22, and chitosan], environmental factors (darkness, $\mathrm{CO}_{2}$, ultraviolet- $\mathrm{B}$ radiation) and even polyamines (Table 1). There have been several reviews on the role of NO in plants, emphasizing the importance of NO in plants, particularly in stomatal closure (Agurla and Raghavendra 2016, Agurla et al. 2018a, Hancock and Neill 2019, Kolbert et al. 2019a, b).
Since the past two decades, the role of gasotransmitters in modulating stomatal closure, as a part of plant innate immunity response to protect against biotic/abiotic stress conditions has drawn considerable attention (García-Mata and Lamattina 2013, Scuffi et al. 2016, Yao et al. 2019). Examples of such gasotransmitters that induce stomatal closure are $\mathrm{NO}$, carbon monoxide $(\mathrm{CO})$ and hydrogen sulfide $\left(\mathrm{H}_{2} \mathrm{~S}\right)$. Gasotransmitters have to fulfill specific criteria, such as small size, ability to pass freely across the biological membranes, no involvement of receptors, specific effects at physiological concentration, enzymatic and regulated production, specific molecular targets, and finally the application of their donors can mimic their functions (Wang et al. 2002). There are other gaseous 
molecules known to mediate stomatal closure, but are not considered as typical gasotransmitters (see the section on "Stomatal regulation by ethylene and other gaseous molecules").

This article presents an account of gasotransmitters operating in plants, with particular emphasis on stomatal closure. Our primary focus has been on $\mathrm{NO}, \mathrm{CO}$, and $\mathrm{H}_{2} \mathrm{~S}$. The ability of other gaseous molecules, like sulfur dioxide $\left(\mathrm{SO}_{2}\right)$, ozone $\left(\mathrm{O}_{3}\right)$, or ethylene (ET), is pointed out, though these gases are not considered strictly as "gasotransmitters". The interactions among the gasotransmitters, as well as with other signalling components, are highlighted. Finally, concluding remarks are made to emphasize the need for further research on this fascinating topic.

\section{Nitric oxide: dual effects}

Nitric oxide is a vital secondary messenger in various signalling pathways during plant responses to stress (Fancy et al. 2017). On exposure to stress conditions, the elevated ROS amount in guard cells can stimulate NO production and promote stomatal closure. Accumulation of $\mathrm{NO}$ in guard cells appears to be essential for abscisic acid (ABA)induced stomatal closure (Gayatri et al. 2013). Elevated NO releases phosphatidic acid (PA), which can activate NADPH oxidase, to promote ROS production and stomatal closure (Distefano et al. 2008). Parallelly, NO can elevate cytosolic free $\mathrm{Ca}^{2+}$, which modulates ion channels, loss of cations/anions from guard cells, and stomatal closure.

Table 1. Nitric oxide (NO) production and associated events triggered by different compounds/factors in guard cells leading to stomatal closure. MPK - mitogen activated protein kinase, NIA1 - nitrate reductase 1, OST - open stomata, ROS - reactive oxygen species, S1P sphingosine-1-phosphate.

\begin{tabular}{|c|c|c|c|}
\hline Inducer & Plant & Observation & Reference \\
\hline \multicolumn{4}{|l|}{ Hormones and elicitors } \\
\hline Abscisic acid (ABA) & Pisum sativum & rise in $\mathrm{pH}$ precedes the $\mathrm{NO}$ increase & Gonugunta et al. 2008 \\
\hline Salicylic acid (SA) & Arabidopsis thaliana & promotion of nitric oxide synthesis & Sun et al. 2010 \\
\hline Methyl jasmonate (MeJA) & Arabidopsis thaliana & rise in $\mathrm{ROS}$ and $\mathrm{NO}$ & Munemasa et al. 2007 \\
\hline Strigolactone (SL) & Arabidopsis thaliana & marked increase in ROS as well as NO & Lv et al. 2018 \\
\hline Ethylene & Arabidopsis thaliana & $\begin{array}{l}\text { rise in the cytosolic } \mathrm{pH} \text { precedes } \mathrm{NO} \\
\text { production }\end{array}$ & Liu et al. 2010 \\
\hline $\begin{array}{l}\text { Cryptogein, harpin (Microbial } \\
\text { elicitors) }\end{array}$ & Arabidopsis thaliana & rise in $\mathrm{ROS}$ and $\mathrm{NO}$ & Gayatri et al. 2017 \\
\hline Flagellin22 (flg22) & Arabidopsis thaliana & activation of OST1 & Melotto et al. 2006 \\
\hline Chitosan & Solanum lycopersicum & production of ROS as well as NO & Czékus et al. 2020 \\
\hline Lipopolysaccharides (LPS) & Arabidopsis thaliana & induces NO production & Melotto et al. 2006 \\
\hline Yeast elicitor (YEL) & Arabidopsis thaliana & $\begin{array}{l}\text { peroxidase dependent ROS production and } \\
\text { subsequent NO rise }\end{array}$ & Khokon et al. 2010 \\
\hline \multicolumn{4}{|l|}{ Other compounds } \\
\hline $\begin{array}{l}\text { Cyclodipeptides (made of two } \\
\text { residues of proline) }\end{array}$ & Nicotiana benthamiana & $\begin{array}{l}\text { ROS and NO production and enhancement } \\
\text { of cytosolic } \mathrm{Ca} 2+\end{array}$ & Wu et al. 2017 \\
\hline $\begin{array}{l}\text { Polyamines (putrescine, spermine } \\
\text { spermidine) }\end{array}$ & Arabidopsis thaliana & increase in ROS, followed by NO & Agurla et al. $2018 \mathrm{~b}$ \\
\hline Allyl isothiocyanate (AITC) & Vicia faba & $\begin{array}{l}\text { peroxidase dependent ROS production, and } \\
\text { rise in NO }\end{array}$ & Sobahan et al. 2015 \\
\hline Alkalinizer (methylamine) & Pisum sativum & $\begin{array}{l}\text { cytosolic alkalinization promotes the rise } \\
\text { in NO }\end{array}$ & Gonugunta et al. 2008 \\
\hline Sphingolipids (phyto-S1P, S1P) & Pisum sativum & marked rise in $\mathrm{pH}$ as well as $\mathrm{NO}$ & Puli et al. 2016 \\
\hline Hydrogen peroxide & Arabidopsis thaliana & stimulation of NO synthesis & Bright et al. 2006 \\
\hline Bicarbonate & Pisum sativum & $\begin{array}{l}\text { NO production mediated by NOS-like } \\
\text { enzyme }\end{array}$ & Kolla and Raghavendra 2007 \\
\hline \multicolumn{4}{|l|}{ Environmental factors } \\
\hline Ambient $\mathrm{CO} 2$ & Solanum lycopersicum & rise in ROS and NO & Shi et al. 2015c \\
\hline Ultraviolet-B (UV-B) & Arabidopsis thaliana & MPK6 activation and rise in ROS and NO & Li et al. 2017 \\
\hline Darkness & Arabidopsis thaliana & NIA1 dependent NO rise & Zhang et al. 2017 \\
\hline
\end{tabular}




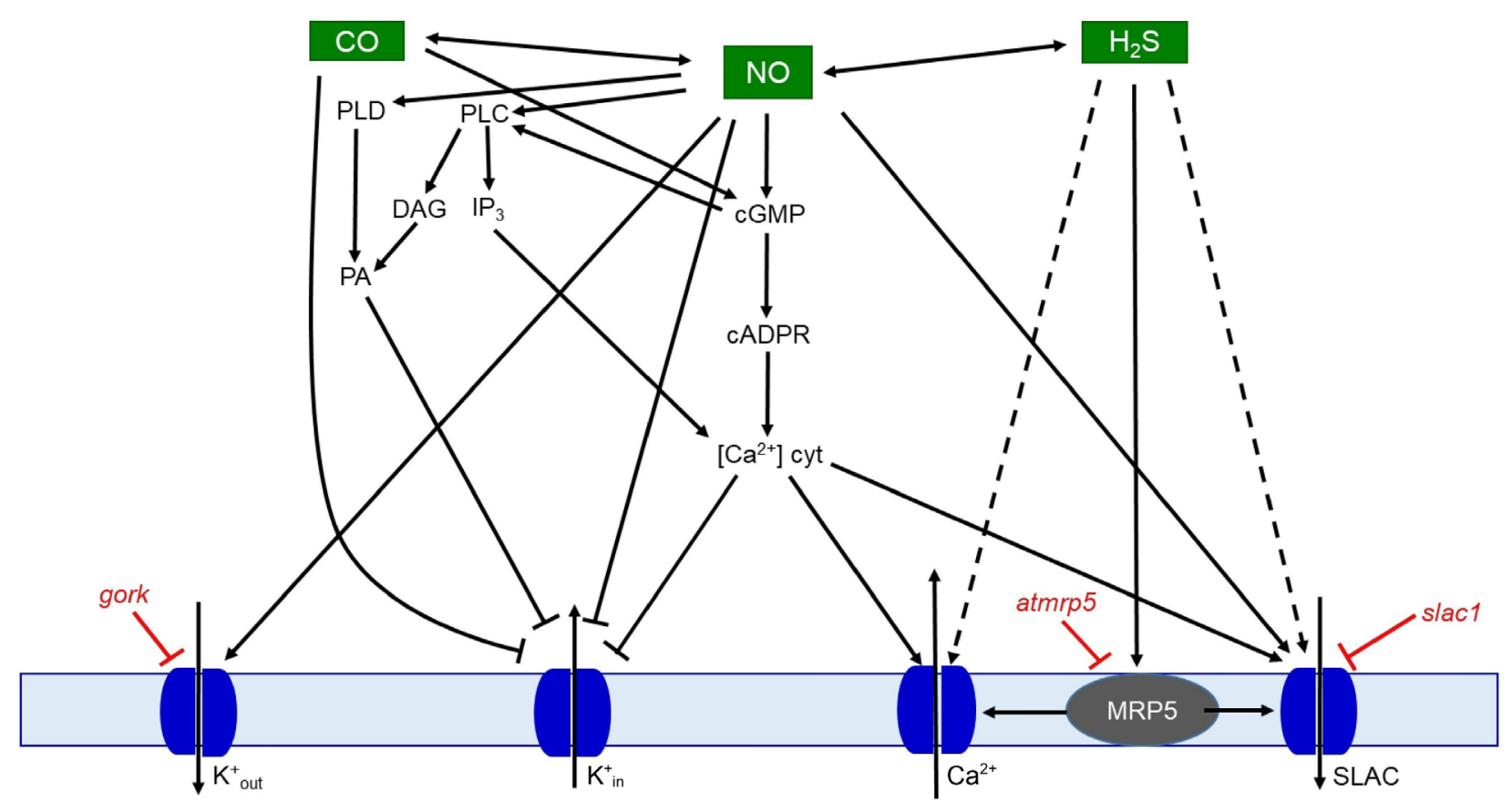

Fig. 2. Events downstream of gasotransmitters leading to the modulation of ion flux and stomatal closure due to the decreased pressure potential in the turgid guard cells. Readers may note the altered position of $\mathrm{CO}$ and $\mathrm{H}_{2} \mathrm{~S}$ from Fig. 1. Any rise in $\mathrm{NO}$ elevates cytosolic free calcium $\left(\mathrm{Ca}^{2+}\right.$-cyt) content in the guard cells by upregulating the chain of cyclic guanosine monophosphate (cGMP)-cyclic ADP ribose (cADPR) and phospholipase C (PLC)-inositol-1,4,5-triphosphate (IP3). In turn, $\mathrm{Ca}^{2+}$ inhibits potassium ion ( $\mathrm{K}^{+}$) influx channels. Additionally, $\mathrm{NO}$ can activate $\mathrm{K}^{+}$out channels as well as slow anion channel 1 (SLAC1), to trigger ion efflux from guard cells. Both CO and $\mathrm{H}_{2} \mathrm{~S}$ can stimulate NADPH oxidase $(\mathrm{RBOH})$, thus ROS production. The $\mathrm{H}_{2} \mathrm{~S}$ regulates both SLAC and $\mathrm{Ca}^{2+}$ channels, but the direct action of $\mathrm{H}_{2} \mathrm{~S}$ is still obscure. The effect of $\mathrm{H}_{2} \mathrm{~S}$ on SLAC can be mediated by a plasma membrane ABC transporter protein (multidrug resistant protein 5, MRP5). Besides inducing stomatal closure, $\mathrm{H}_{2} \mathrm{~S}$ can also reduce the content of $\mathrm{NO}$ and promote the stomatal opening. Red arrows illustrate the use of Arabidopsis mutants (details listed in Table 1 Suppl). Other abbreviations: DAG - diacylglycerol; NO nitric oxide; PA - phosphatidic acid; PLD - phospholipase D.

The regulation of various components by NO leading to stomatal closure is described in the following section.

In contrast, NO can also interfere with ABA signalling by restricting ROS production due to post-translational modifications (PTMs) of some pivotal proteins and down-regulation of their activity (Laxalt et al. 2016). S-nitrosylation of open stomata 1 (OST1) and NADPH oxidase $\mathrm{rbohD} / \mathrm{F}$ disrupts the enzymatic activity and lowers ROS, required for stomatal closure. Even the S-nitrosylation of ABA receptor can lead to inhibition of protein phosphatase $2 \mathrm{C}$, showing the opposite effect to stomatal closure. Such a dual role of NO to promote and inhibit stomatal closure and their mechanisms involved need to be studied in future.

\section{Mechanism of stomatal closure by NO}

The mechanism of action of NO can be through multiple ways (Fig. 2). An important consequence of the rise in $\mathrm{NO}$ is the increase in $\mathrm{Ca}^{2+}$ in guard cells. Elevated NOmediated guanyl cyclase dependent increase in cyclic guanosine monophosphate (cGMP) production, raising the content of cyclic ADP ribose (cADPR) and release of $\mathrm{Ca}^{2+}$ from internal sources (García-Mata et al. 2003). Parallelly, NO promoted the activities of phospholipase C (PLC) or phospholipase D (PLD). Inositol 1,4,5-trisphosphate (IP3) produced from PLC induces the release of $\mathrm{Ca}^{2+}$. Together, the rise in cytosolic $\mathrm{Ca}^{2+}$ inhibits $\mathrm{K}^{+}$influx channel and activates slow anion channel (SLAC), leading to stomatal closure (Gayatri et al. 2013, Arnaud and Hwang 2015, Agurla et al. 2018a). Selected downstream components regulated by NO in the guard cell are listed in Table 2. Besides, causing an increase in $\mathrm{Ca}^{2+}$ content, the rise in NO promotes PTMs, as described in the following section.

Arabidopsis mutants had been excellent tools to dissect and understand the mechanisms of NO production and action on stomatal closure. A detailed list of such Arabidopsis mutants studied for unraveling the role of NO in guard cells is given in Appendix (Table 1 Suppl).

\section{Post-translational modifications mediated by gasotransmitters}

Post-translational modification (PTM) of specific amino acid residues causes marked changes in protein structure and function. The rise in NO can initiate PTM of selected proteins. Reversible covalent attachment of NO to the thiol group of cysteine or tyrosine forming an S-nitrosothiol (S-nitrosylation) in stress-related proteins and signalling components are well documented (Neill et al. 2008, Agurla 
Table 2. Downstream components modulated by nitric oxide (NO) during stomatal closure. cADPR - cyclic ADP ribose, cGMP - cyclic guanosine monophosphate, GORK - guard cell outward-rectifying $\mathrm{K}^{+}$channel, OST - open stomata, PLC - phospholipase C, PLD phospholipase D, PYL - pyrabactin resistance-like, PYR - pyrabactin resistance, RCAR - regulatory component of ABA receptors.

\begin{tabular}{|c|c|c|c|}
\hline Target & Consequences of $\mathrm{NO}$ action & Plant & Reference \\
\hline Calcium channel & $\begin{array}{l}\text { release of } \mathrm{Ca} 2+\text { from internal stores mediated by IP } 3 \\
\text { and cADPR }\end{array}$ & $\begin{array}{l}\text { Vicia faba } \\
\text { review }\end{array}$ & $\begin{array}{l}\text { García-Mata et al. } 2003 \\
\text { Gayatri et al. } 2013\end{array}$ \\
\hline Slow anion channel (SLAC) & upregulation of anion efflux & review & Gayatri et al. 2013 \\
\hline Non-expressor of PR1 (NPR1) & S-nitrosylation of NPR1 & review & Yu et al. 2014 \\
\hline Phosphatidic acid (PA) & $\begin{array}{l}\text { inhibition of } \mathrm{K}^{+} \text {influx and activation of } \mathrm{NADPH} \\
\text { oxidase }\end{array}$ & Vicia faba & Distefano et al. 2008 \\
\hline Potassium influx channel & inhibition of $\mathrm{K}^{+}$channel by elevated cytosolic $\mathrm{Ca}^{2+}$ & Vicia faba & Zhao et al. 2013 \\
\hline Outward-rectifying $\mathrm{K}^{+}$channel & $\begin{array}{l}\text { inactivation of GORK due to nitrosylation of channel } \\
\text { proteins }\end{array}$ & Vicia faba & Sokolovski and Blatt 2004 \\
\hline PYR/PYL/RCAR & inactivation of $\mathrm{ABA}$ receptors due to tyrosine nitration & opinion & Laxalt et al. 2016 \\
\hline OST1 & $\begin{array}{l}\text { inactivation due to nitrosylation of ABA receptors and } \\
\text { OST1 }\end{array}$ & opinion & Laxalt et al. 2016 \\
\hline NADPH oxidase & NADPH oxidase inactivation due to S-nitrosylation & opinion & Laxalt et al. 2016 \\
\hline cGMP and cADPR & $\begin{array}{l}\text { activation of guanyl cyclase, rise in cADPR, } \mathrm{Ca} 2+ \\
\text { release }\end{array}$ & Vicia faba & García-Mata et al. 2003 \\
\hline PLC & production of PA & $\begin{array}{l}\text { Arabidopsis } \\
\text { thaliana }\end{array}$ & Uraji et al. 2012 \\
\hline PLD & production of PA & Vicia faba & Distefano et al. 2008 \\
\hline
\end{tabular}

et al. 2014, Sehrawat and Deswal 2014, Yu et al. 2014, Gross and Durner 2016). PTMs such as phosphorylation and dephosphorylation also play an essential role in stomatal movement (Zhang et al. 2014). Phosphorylation of $\mathrm{H}^{+}$-ATPase in response to blue radiation-induced stomatal opening was reported (Takemiya et al. 2013). Phosphatase mediated dephosphorylation prevented stomatal closure by down-regulating the protein kinases (Yang et al. 2017). ROS generated during ABA signalling initiate these phosphorylation events (Balmant et al. 2016).

In contrast to ROS, NO-mediated PTMs are S-nitrosylation, S-nitration, S-sulfihydration, and S-guanylation. S-nitrosylation of OST1/SnRK2.6 inhibited the kinase activity and prevented stomatal closure (Fancy et al. 2017). A bacterial peptide, flg22, induced stomatal closure in Arabidopsis, by the rise in ROS and then NO, followed by nitrosylation of several proteins (Lawrence et al. 2020). Persulfidation/S-sulfihydration is the second major PTM after nitrosylation, which can protect against oxidative damage. Almost $50 \%$ of the cytosolic proteins were persulfidated in plants, with many of the proteins involved in stress responses (Gotor et al. 2019). Glutathionylation and S-guanylation are the other PTMs, promoted by NO. Dehydroascorbate reductase was glutathionylated in Arabidopsis (Honda et al. 2015, Sami et al. 2018). Selected examples of PTMs and their role during stomatal closure are listed in Table 2 Suppl.

Carbonylation, sumoylation, and ubiquitination, are also among the PTMs, but their role regarding NO or CO or $\mathrm{H}_{2} \mathrm{~S}$ is not clear. A cross-talk can occur between NO- induced nitrosylation and ROS-induced carbonylation (Lounifi et al. 2013).

\section{$\mathrm{CO}$ and $\mathrm{H}_{2} \mathrm{~S}$ : two gasotransmitters other than $\mathrm{NO}$}

Besides NO, two more gasotransmitters, $\mathrm{CO}$ and $\mathrm{H}_{2} \mathrm{~S}$, promote stomatal closure (García-Mata and Lamattina 2013, Scuffi et al. 2016). The ability of CO to close stomata could be due to the binding of gas to heme proteins (Song et al. 2008), based on the evidence that the closure induced by $\mathrm{CO}$ was relieved by hemoglobin (a $\mathrm{CO} / \mathrm{NO}$ scavenger). Stomatal closure caused by hematin and $\mathrm{CO}$ gas was reversed by 2-(4-carboxyphenyl)-4,4,5,5tetramethylimidazoline-1-oxyl-3-oxide (cPTIO) and N(gamma)-nitro-L-arginine methyl ester (L-NAME), reflecting the similarity between the action of $\mathrm{CO}$ and $\mathrm{NO}$ on stomata (Song et al. 2008).

In plants, the degradation of heme by heme oxygenase (HO) can produce CO (Song et al. 2008). Among the three $\mathrm{HO}$ isoforms, HO1 was the primary enzymatic source of $\mathrm{CO}$ production (He and He 2014). In Vicia faba leaves, $\mathrm{CO}$ production and $\mathrm{HO}$ activity increased in response to ABA treatment, resulting in stomatal closure (Wang and Liao 2016, Cao et al. 2007). Both NO and cGMP were downstream components of CO signalling in stomatal guard cells (Cao et al. 2007). Stomatal closure induced by $\mathrm{CO}$ was dependent on the $\mathrm{H}_{2} \mathrm{O}_{2}$ signalling pathway in $V$. faba (She and Song 2008). Thus, CO and NO exhibited similar regulation in the stomatal movement. 
Hydrogen sulfide $\left(\mathrm{H}_{2} \mathrm{~S}\right)$ is the third gasotransmitter after $\mathrm{NO}$ and $\mathrm{CO}$, which can mediate stomatal closure in response to different stimuli (Scuffi et al. 2016). For example, $\mathrm{H}_{2} \mathrm{~S}$ was an essential component of stomatal closure induced by ABA and ethylene (ET) during drought adaptation (Wang et al. 2015). $\mathrm{H}_{2} \mathrm{~S}$ acted downstream of NADPH oxidase during stomatal closure induced by ABA, or ET, or NO (Hou et al. 2013, Scuffi et al. 2014, 2018). Stomatal closure by $\mathrm{H}_{2} \mathrm{~S}$ was also similar to that by $\mathrm{ABA}$ in regulating $\mathrm{K}^{+}, \mathrm{Ca}^{2+}$, and $\mathrm{Cl}^{-}$transport in guard cells, when plants were exposed to drought stress (Jin et al. 2013, Malcheska et al. 2017). Scuffi et al. (2014) observed that $\mathrm{H}_{2} \mathrm{~S}$ was enzymatically produced from cysteine by L/D-cysteine desulfhydrase (L/D-DES). Even exogenous $\mathrm{H}_{2} \mathrm{~S}$ could induce stomatal closure in Vicia faba and Arabidopsis thaliana, by activating SLAC via $\mathrm{Ca}^{2+}$ (Wang et al. 2016).

A cross-talk between the three gasotransmitters: NO, $\mathrm{CO}$, and $\mathrm{H}_{2} \mathrm{~S}$, may be operating in guard cells. $\mathrm{H}_{2} \mathrm{~S}$ and $\mathrm{NO}$ regulate each other source by modulating the enzymatic production of the other (Scuffi et al. 2016). Lack of endogenous $\mathrm{NO}$ significantly reduced the effect of $\mathrm{H}_{2} \mathrm{~S}$ on stomatal closure, implying that $\mathrm{NO}$ acted downstream of $\mathrm{H}_{2} \mathrm{~S}$ (Pandey 2014). Both $\mathrm{H}_{2} \mathrm{~S}$ and $\mathrm{NO}$ were involved in the signal transduction pathway of ET-or ABA-induced stomatal closure (Liu et al. 2011, Wang et al. 2015).

\section{Stomatal regulation by ethylene and other gaseous molecules}

Ethylene, a gaseous phytohormone, is actively involved in stomatal function besides plant growth and development (Acharya et al. 2009). However, it is not clear if ET promotes or interferes with stomatal closure. Application of ethepon (an ET releasing compound) or 1-aminocyclopropane-1-carboxylic acid (ACC) helped stomatal closure in Arabidopsis leaves (Desikan et al. 2006). Cytosolic alkalization and NO generation were vital for ET induced reduction of stomatal aperture (Shi et al. 2017). ET-induced stomatal closure was associated with NADPH oxidase (AtrbohD/F)-dependent $\mathrm{H}_{2} \mathrm{O}_{2}$ production targeting S-type anion channels (Ge et al. 2015, Munemasa et al. 2019).

In contrast, ET was antagonistic to ABA and MeJA and interacted also with 24-epibrassinolide and even UV or $\mathrm{H}_{2} \mathrm{~S}$ during stomatal closure (Huang et al. 2008, Shi et al. 2015a, Munemasa et al. 2019). We believe that the indirect action of ET by its interaction with other hormones dominates over its likely direct effect on stomata. Further description of ET effects on stomata can be found in the reviews of Acharya et al. (2009) and DaszkowskaGolec and Szarejko (2013). Although a potent regulator of stomatal function and a gaseous molecule, ET is not considered as a gasotransmitter as it is perceived by a wellcharacterized receptor complex (Kolbert et al. 2019b).

Ozone, an atmospheric pollutant (and an oxidant), promotes the rise in ROS in plant tissues while triggering the synthesis of plant hormones, such as ET, SA, and jasmonic acid (Tamaoki 2008). Ozone induced $\mathrm{H}_{2} \mathrm{O}_{2}$ can up-regulate NO production in guard cells, stimulate SLAC1, and close stomata (Kangasjärvi et al. 2005, Kollist et al. 2007, Vahisalu et al. 2010). Another pollutant gas, $\mathrm{SO}_{2}$, also closed stomata, but the mechanism was not understood (Ooi et al. 2019). Bicarbonate, a form of $\mathrm{CO}_{2}$ induced stomatal closure by elevating $\mathrm{H}_{2} \mathrm{O}_{2}$ as well as $\mathrm{NO}$ in guard cells of Arabidopsis (Kolla et al. 2007, Kolla and Raghavendra 2007). Elevated $\mathrm{CO}_{2}$ promoted stomatal closure by activating SLAC1 in guard cells (Poschenrieder et al. 2018).

Methane $\left(\mathrm{CH}_{4}\right.$, a greenhouse gas), promoted stomatal closure. $\mathrm{CH}_{4}$ induced stomatal closure appeared to be due to the increased sensitivity towards ABA of methyl-coenzyme $\mathrm{M}$ reductase, the enzymatic source of $\mathrm{CH}_{4}$ (Su et al. 2019). Since ammonia $\left(\mathrm{NH}_{3}\right)$ and $\mathrm{CH}_{4}$ appear to qualify the criteria, they may be potential candidates as gasotransmitters (Pei et al. 2018).

\section{The relevance of $\mathrm{NO} / \mathrm{CO} / \mathrm{H}_{2} \mathrm{~S}$ to the plant innate immunity}

The role of $\mathrm{NO}$ in plant innate immunity had been emphasized (Agurla et al. 2014, Rosnoblet et al. 2016, Mur et al. 2017). The production of ROS, as well as NO, was a common feature in response to pathogen infection or elicitors. Similarly, microbe-associated molecular patterns initiated innate immune defense is activating by downstream components, like NO production (Newman et al. 2013, Héloir et al. 2019). Upon invasion of pathogens onto the leaf surface, a series of signalling events ensure stomatal closure to restrict the further entry of pathogens. The secondary messenger, $\mathrm{NO}$, is a pivotal component during such defense responses (Ma et al. 2016). A strong association exists between $\mathrm{H}_{2} \mathrm{~S}$ content in plants and their defense responses to pathogen attack (Calderwood et al. 2014, Shi et al. 2015b, Li et al. 2016). The enzyme L/DDES and its product $\mathrm{H}_{2} \mathrm{~S}$ helped in defense responses against the bacterial pathogens by activating SA signallingrelated genes and confer abiotic stress tolerance (Shi et al. 2015b). Since $\mathrm{H}_{2} \mathrm{~S}$ is known to have a synergistic effect with ROS during oxidative stress responses, such interaction can also provide defense against biotic stresses by stomatal closure (Tao et al. 2020).

We could not find any report on the direct ability of $\mathrm{CO}$ to impart pathogen resistance. However, the interactions of $\mathrm{CO}$ with NO may play a role in the abiotic stress responses of plants. readers interested in further details on the roles of $\mathrm{H}_{2} \mathrm{~S}$ and $\mathrm{CO}$ can refer to some of the recent reviews (Shekhawat and Verma 2010, He and He 2014, Li et al. 2016, Tao et al. 2020).

\section{Concluding remarks}

Of the three signalling molecules considered as gasotransmitters, NO is undoubtedly the most studied and well-accepted player during stomatal closure (Gayatri et al. 2013, Hancock and Neill 2019). However, it is necessary to establish the origin of NO in plants. Unlike the case 
of animal cells, where an inducible nitric oxide synthase (NOS) provides the primary source of NO, the status in plants is far from clear. The relative roles of NR, NOS-like enzyme, and even others like HO need to be re-examined, and their importance be established. The interaction between NO and ROS is intriguing as NO can play a dual role of oxidant and anti-oxidant (Agurla and Raghavendra 2016). The abundance of both ROS and NO could cause a synergistic effect because peroxynitrite (formed by the combination of ROS and NO) can be a more powerful regulator than either ROS or NO alone (Vandelle and Delledonne 2011).

The origin and mechanism of action of the other two gasotransmitters, $\mathrm{H}_{2} \mathrm{~S}$ and $\mathrm{CO}$, are exciting but intriguing. Despite being a potent metabolic, respiratory poison, the role of $\mathrm{CO}$ as a signal to promote stomatal closure and plant innate immunity warrants further studies. On the other hand, being an essential component of sulfur metabolism, the importance of $\mathrm{H}_{2} \mathrm{~S}$ as a signal to modulate stomatal function appears to be physiologically relevant. Strong interactions occurred between ROS, NO, $\mathrm{H}_{2} \mathrm{~S}$, and CO (Hancock and Whiteman 2016, Wang and Liao 2016). Reports were indicating that NO could promote the activity of $\mathrm{HO}$ and $\mathrm{H}_{2} \mathrm{~S}$ content, while $\mathrm{CO}$ can up-regulate the release of NO (Song et al. 2008, Santa-Cruz et al. 2010). Further experiments are needed to establish if there is a master-player among $\mathrm{NO}, \mathrm{CO}$, and $\mathrm{H}_{2} \mathrm{~S}$ or if all the three are capable of acting independently.

\section{References}

Acharya, B.R., Assmann, S.M.: Hormone interactions in stomatal function. - Plant mol. Biol. 69: 451-462, 2009.

Agurla S., Gahir S., Munemasa S., Murata Y., Raghavendra A.S.: Mechanism of stomatal closure in plants exposed to drought and cold stress. - In: Iwaya-Inoue, M., Sakurai, M., Uemura, M. (ed.): Advances in Experimental Medicine and Biology. Vol. 1081: Survival Strategies in Extreme Cold and Desiccation. Pp. 215-232. Springer, Singapore 2018a.

Agurla, S., Gayatri, G., Raghavendra, A.S.: Nitric oxide as a secondary messenger during stomatal closure as a part of plant immunity response against pathogens. - Nitric Oxide 43: 89-96, 2014.

Agurla, S., Gayatri, G., Raghavendra, A.S.: Polyamines increase nitric oxide and reactive oxygen species in guard cells of Arabidopsis thaliana during stomatal closure. - Protoplasma 255: 153-162, 2018 b.

Agurla, S., Raghavendra, A.S.: Convergence and divergence of signaling events in guard cells during stomatal closure by plant hormones or microbial elicitors. - Front. Plant Sci. 7: 1332, 2016.

Alcázar, R., Cuevas, J.C., Patron, M., Altabella, T., Tiburcio, A.F.: Abscisic acid modulates polyamine metabolism under water stress in Arabidopsis thaliana. - Physiol. Plant. 128: 448-455, 2006.

Arnaud, D., Hwang, I.: A sophisticated network of signaling pathways regulates stomatal defenses to bacterial pathogens. - Mol. Plant 8: 566-581, 2015.

Balmant, K.M., Zhang, T., Chen, S.: Protein phosphorylation and redox modification in stomatal guard cells. - Front. Physiol. 7: 26, 2016.
Bright, J., Desikan, R., Hancock, J.T., Weir, I.S., Neill, S.J.: ABAinduced $\mathrm{NO}$ generation and stomatal closure in Arabidopsis are dependent on $\mathrm{H}_{2} \mathrm{O}_{2}$ synthesis. - Plant J. 45: 113-122, 2006.

Calderwood, A., Kopriva, S.: Hydrogen sulfide in plants: from dissipation of excess sulfur to signaling molecule. - Nitric Oxide 41: 72-78, 2014.

Cao, Z.Y., Huang, B.K., Wang, Q.Y., Xuan, W., Ling, T.F., Zhang, B.: Involvement of carbon monoxide produced by heme oxygenase in ABA-induced stomatal closure in Vicia $f a b a$ and its proposed signal transduction pathway. - Chin. Sci. Bull. 52: 2365-2373, 2007.

Chen, Z.H., Wang, Y., Wang, J.W., Babla, M., Zhao, C., GarcíaMata, C., Sani, E., Differ, C., Mak, M., Hills, A. Amtmann, A.: Nitrate reductase mutation alters potassium nutrition as well as nitric oxide-mediated control of guard cell ion channels in Arabidopsis. - New Phytol. 209: 1456-1469, 2016.

Czékus, Z., Poór, P., Tari, I., Ördög, A.: Effects of light and daytime on the regulation of chitosan-induced stomatal responses and defence in tomato plants. - Plants 9: DOI: 10.3390/plants9010059, 2020.

Daszkowska-Golec, A., Szarejko, I.: Open or close the gate stomata action under the control of phytohormones in drought stress conditions. - Front. Plant Sci. 4: 138, 2013.

Desikan, R., Last, K., Harrett-Williams, R., Tagliavia, C., Harter, K., Hooley, R., Hancock, J.T., Neill, S.J.: Ethylene-induced stomatal closure in Arabidopsis occurs via AtrbohF-mediated hydrogen peroxide synthesis. - Plant J. 47: 907-916, 2006.

Distefano, A.M., García-Mata, C., Lamattina, L., Laxalt, A.M.: Nitric oxide-induced phosphatidic acid accumulation: a role for phospholipases C and D in stomatal closure. - Plant Cell Environ. 31: 187-194, 2008.

Fancy, N.N., Bahlmann, A.K., Loake, G.J.: Nitric oxide function in plant abiotic stress. - Plant Cell Environ. 40: 462-472, 2017.

García-Mata, C., Gay, R., Sokolovski, S., Hills, A., Lamattina, L., Blatt, M.R.: Nitric oxide regulates $\mathrm{K}^{+}$and $\mathrm{Cl}^{-}$channels in guard cells through a subset of abscisic acid-evoked signaling pathways. - Proc. nat. Acad. Sci. USA 100: 11116-11121, 2003.

García-Mata, C., Lamattina, L.: Gasotransmitters are emerging as new guard cell signaling molecules and regulators of leaf gas exchange. - Plant Sci. 201: 66-73, 2013.

Gayatri, G., Agurla, S., Kuchitsu, K., Anil, K., Podile, A.R., Raghavendra, A.S.: Stomatal closure and rise in ROS/NO of Arabidopsis guard cells by tobacco microbial elicitors: Cryptogein and Harpin. - Front. Plant Sci. 8: 1096, 2017.

Gayatri, G., Agurla, S., Raghavendra, A.S.: Nitric oxide in guard cells as an important secondary messenger during stomatal closure. - Front. Plant Sci. 4: 425, 2013.

Ge, X. M., Cai, H.L., Lei, X., Zhou, X., Yue, M., He, J.M.: Heterotrimeric $G$ protein mediates ethylene-induced stomatal closure via hydrogen peroxide synthesis in Arabidopsis. Plant J. 82: 138-150, 2015

Gonugunta, V.K., Srivastava, N., Puli, M.R., Raghavendra, A.S.: Nitric oxide production occurs after cytosolic alkalinization during stomatal closure induced by abscisic acid. - Plant Cell Environ. 31: 1717-1724, 2008.

Gotor, C., García, I., Aroca, Á., Laureano-Marín, A.M., ArenasAlfonseca, L., Jurado-Flores, A., Moreno, I., Romero, L.C.: Signaling by hydrogen sulfide and cyanide through posttranslational modification. - J. exp. Bot. 70: 4251-4265, 2019.

Gross, I., Durner, J.: In search of enzymes with a role in 3', 5 '-cyclic guanosine monophosphate metabolism in plants. Front. Plant Sci. 7: 576, 2016.

Guo, F.Q., Okamoto, M., Crawford, N.M.: Identification of a plant nitric oxide synthase gene involved in hormonal signaling. - Science 302: 100-103, 2003. 
Hancock, J.T., Neill, S.J.: Nitric Oxide: Its generation and interactions with other reactive signaling compounds. - Plants 8: 41, 2019.

Hancock, J.T., Whiteman, M.: Hydrogen sulfide signaling: interactions with nitric oxide and reactive oxygen species. Ann. New York Acad. Sci. 1365: 5-14, 2016.

He, H., He, L.: Heme oxygenase 1 and abiotic stresses in plants. - Acta Physiol. Plant. 36: 581-588, 2014.

Héloir, M.C., Adrian, M., Brulé, D., Claverie, J., Cordelier, S., Daire, X., Dorey, S., Gauthier, A., Lemaître-Guillier, C., Negrel, J., Trdá, L.: Recognition of elicitors in grapevine: from MAMP and DAMP perception to induced resistance. Front. Plant Sci. 10: 1117, 2019.

Hetherington, A.M., Woodward, F.I.: The role of stomata in sensing and driving environmental change. - Nature 424: 901908, 2003.

Honda, K., Yamada, N., Yoshida, R., Ihara, H., Sawa, T., Akaike, T., Iwai, S.: 8-Mercapto-cyclic GMP mediates hydrogen sulfide-induced stomatal closure in Arabidopsis. - Plant Cell Physiol. 56: 1481-1489, 2015.

Hou, Z., Wang, L., Liu, J., Hou, L., Liu, X.: Hydrogen sulfide regulates ethylene-induced stomatal closure in Arabidopsis thaliana. - J. integr. Plant Biol. 55: 277-289, 2013.

Huang, D., Wu, W., Abrams, S.R., Cutler, A.J.: The relationship of drought-related gene expression in Arabidopsis thaliana to hormonal and environmental factors. - J. exp. Bot. 59: 29913007, 2008.

Jin, Z., Xue, S., Luo, Y., Tian, B., Fang, H., Li, H., Pei, Y.: Hydrogen sulfide interacting with abscisic acid in stomatal regulation responses to drought stress in Arabidopsis. - Plant Physiol. Biochem. 62: 41-46, 2013.

Kangasjärvi, J., Jaspers, P., Kollist, H.: Signalling and cell death in ozone-exposed plants. - Plant Cell Environ. 28: 1021-1036, 2005.

Khokon, M.A.R., Hossain, M.A., Munemasa, S., Uraji, M., Nakamura, Y., Mori, I.C., Murata, Y.: Yeast elicitor-induced stomatal closure and peroxidase-mediated ROS production in Arabidopsis. - Plant Cell Physiol. 51: 1915-1921, 2010.

Kolbert, Z., Barroso, J.B., Brouquisse, R., Corpas, F.J., Gupta, K.J., Lindermayr, C., Loake, G.J., Palma, J.M., Petřivalský, M., Wendehenne, D., Hancock, J.T.: A forty-year journey: the generation and roles of NO in plants. - Nitric Oxide 93: 5370, 2019a.

Kolbert, Z., Feigl, G., Freschi, L., Poór, P.: Gasotransmitters in action: nitric oxide-ethylene crosstalk during plant growth and abiotic stress responses. - Antioxidants 8: 167, $2019 \mathrm{~b}$.

Kolla, V.A., Raghavendra, A.S., Nitric oxide is a signaling intermediate during bicarbonate-induced stomatal closure in Pisum sativum. - Physiol. Plant. 130: 91-98, 2007.

Kolla, V.A., Vavasseur, A., Raghavendra, A.S.: Hydrogen peroxide production is an early event during bicarbonate induced stomatal closure in abaxial epidermis of Arabidopsis. - Planta 225: 1421-1429, 2007.

Kollist, T., Moldau, H., Rasulov, B., Oja, V., Rämma, H., Hüve, K., Jaspers, P., Kangasjärvi, J., Kollist, H.: A novel device detects a rapid ozone-induced transient stomatal closure in intact Arabidopsis and its absence in abi2 mutant. - Physiol. Plant. 129: 796-803, 2007.

Lawrence, S.R., Gaitens, M., Guan, Q., Dufresne, C., Chen, S.: $\mathrm{S}$-nitroso-proteome revealed in stomatal guard cell response to Flg22. - Int. J. mol. Sci. 21: 1688, 2020.

Laxalt, A.M., García-Mata, C., Lamattina, L.: The dual role of nitric oxide in guard cells: promoting and attenuating the ABA and phospholipid-derived signals leading to the stomatal closure. - Front. Plant Sci. 7: 476, 2016.

Li, F.C., Wang, J., Wu, M.M., Fan, C.M., Li, X., He, J.M.:
Mitogen-activated protein kinase phosphatases affect UV-Binduced stomatal closure via controlling NO in guard cells. - Plant Physiol. 173: 760-770, 2017.

Li, Z.G., Min, X., Zhou, Z.H.: Hydrogen sulfide: a signal molecule in plant cross-adaptation. - Front. Plant Sci. 7: 1621, 2016.

Liu, J., Hou, L., Liu, G., Liu, X., Wang, X.: Hydrogen sulfide induced by nitric oxide mediates ethylene-induced stomatal closure of Arabidopsis thaliana. - Chin. Sci. Bull. 56: 35473553, 2011.

Liu, J., Liu, G., Hou, L., Liu, X.: Ethylene-induced nitric oxide production and stomatal closure in Arabidopsis thaliana depending on changes in cytosolic pH. - Chin. Sci. Bull. 55: 2403-2409, 2010.

Lounifi, I., Arc, E., Molassiotis, A., Job, D., Rajjou, L., Tanou, G.: Interplay between protein carbonylation and nitrosylation in plants. - Proteomics 13: 568-578, 2013.

Lv, S., Zhang, Y., Li, C., Liu, Z., Yang, N., Pan, L., Wu, J., Wang, J., Yang, J., Lv, Y., Zhang, Y.: Strigolactone-triggered stomatal closure requires hydrogen peroxide synthesis and nitric oxide production in an abscisic acid-independent manner. - New Phytol. 217: 290-304, 2018.

Ma, Y., Berkowitz, G.A.: $\mathrm{NO}$ and $\mathrm{Ca}^{2+}$ : critical components of cytosolic signaling systems involved in stomatal immune responses. - Adv. Bot. Res. 77: 285-323, 2016.

Malcheska, F., Ahmad, A., Batool, S., Müller, H.M., LudwigMüller, J., Kreuzwieser, J., Randewig, D., Hänsch, R., Mendel, R.R., Hell, R. Wirtz, M.: Drought-enhanced xylem sap sulfate closes stomata by affecting ALMT12 and guard cell ABA synthesis. - Plant Physiol. 174: 798-814, 2017.

Melotto, M., Underwood, W., Koczan, J., Nomura, K., He, S.Y.: Plant stomata function in innate immunity against bacterial invasion. - Cell 126: 969-980, 2006.

Melotto, M., Zhang, L., Oblessuc, P.R., He, S.Y.: Stomatal defense a decade later. - Plant Physiol. 174: 561-571, 2017.

Munemasa, S., Hauser, F., Park, J., Waadt, R., Brandt, B., Schroeder, J.I.: Mechanisms of abscisic acid-mediated control of stomatal aperture. - Curr. Opin. Plant Biol. 28: 154-162, 2015.

Munemasa, S., Hirao, Y., Tanami, K., Mimata, Y., Nakamura, Y., Murata, Y.: Ethylene inhibits methyl jasmonate-induced stomatal closure by modulating guard cell slow-type anion channel activity via the OPEN STOMATA 1/SnRK2. 6 kinaseindependent pathway in Arabidopsis. - Plant Cell Physiol. 60: 2263-2271, 2019.

Munemasa, S., Oda, K., Watanabe-Sugimoto, M., Nakamura, Y., Shimoishi, Y., Murata, Y.: The coronatine-insensitive 1 mutation reveals the hormonal signaling interaction between abscisic acid and methyl jasmonate in Arabidopsis guard cells. Specific impairment of ion channel activation and second messenger production. - Plant Physiol. 143: 1398-1407, 2007.

Mur, L. A. J., Simpson, C., Kumari, A., Gupta, A.K., Gupta, K. J.: Moving nitrogen to the centre of plant defence against pathogens. - Ann. Bot. 119: 703-709, 2017.

Neill, S., Barros, R., Bright, J., Desikan, R., Hancock, J., Harrison, J., Morris, P., Ribeiro, D., Wilson, I.: Nitric oxide, stomatal closure, and abiotic stress. - J. exp. Bot. 59: 165-176, 2008.

Newman, M.A., Sundelin, T., Nielsen, J.T., Erbs, G.: MAMP (microbe-associated molecular pattern) triggered immunity in plants. - Front. Plant Sci. 4: 139, 2013.

Ooi, L., Matsuura, T., Munemasa, S., Murata, Y., Katsuhara, M., Hirayama, T., Mori, I. C.: The mechanism of $\mathrm{SO}_{2}$-induced stomatal closure differs from $\mathrm{O}_{3}$ and $\mathrm{CO}_{2}$ responses and is mediated by nonapoptotic cell death in guard cells. - Plant Cell Environ. 42: 437-447, 2019. 
Pandey, S.: Hydrogen Sulfide: a new node in the abscisic aciddependent guard cell signaling network? - Plant Physiol. 166: 1680, 2014.

Pei, Y., Jin, Z., Liu, Z., Fang, H., Zhang, L., Hao, X., Liu, D., Du, X., Zhang, Y., Tian, B., Ma, X.: Gasotransmitters in Plants. - In: Wang, R. (ed.): Metallobiology. Series No. 12: Gasotransmitters.: Pp. 235-282, Royal Society of Chemistry, London 2018.

Poschenrieder, C., Fernández, J.A., Rubio, L., Pérez, L., Terés, J., Barceló, J.: Transport and use of bicarbonate in plants: current knowledge and challenges ahead. - Int. J. mol. Sci. 19: 1352, 2018.

Puli, M.R., Rajsheel, P., Aswani, V., Agurla, S., Kuchitsu, K., Raghavendra, A.S.: Stomatal closure induced by phytosphingosine-1-phosphate and sphingosine-1-phosphate depends on nitric oxide and $\mathrm{pH}$ of guard cells in Pisum sativum. - Planta 244: 831-841, 2016.

Raghavendra, A.S., Murata, Y.: Signal transduction in stomatal guard cells. - Front. Plant Sci 8: 114, 2017.

Rosnoblet, C., Bourque, S., Nicolas-Francès, V., Lamotte, O., Besson-Bard, A., Jeandroz, S., Wendehenne, D.: NO signalling in plant immunity. - In: García-Mata, C., Lamattina, L (ed.): Gasotransmitters in Plants. Pp. 219-238, Springer, Dordrecht 2016.

Ruiz-May, E., Segura-Cabrera, A., Elizalde-Contreras, J. M., Shannon, L. M., Loyola-Vargas, V. M.: A recent advance in the intracellular and extracellular redox post-translational modification of proteins in plants. - J. Mol. Recognition 32: e2754, 2019

Saito, N., Yoshimasa, N., Mori, I.C., Murata, Y.: Nitric oxide functions in both methyl jasmonate signaling and abscisic acid signaling in Arabidopsis guard cells. - Plant Signal. Behav. 4: 119-120, 2009.

Saito, S., Uozumi, N.: Guard cell membrane anion transport systems and their regulatory components: an elaborate mechanism controlling stress-induced stomatal closure. Plants 8: 9, 2019.

Sami, F., Faizan, M., Faraz, A., Siddiqui, H., Yusuf, M., Hayat, S.: Nitric oxide-mediated integrative alterations in plant metabolism to confer abiotic stress tolerance, NO crosstalk with phytohormones and NO-mediated post-translational modifications in modulating diverse plant stress. - Nitric Oxide 73: 22-38, 2018

Santa-Cruz, D.M., Pacienza, N.A., Polizio, A.H., Balestrasse, K.B., Tomaro, M.L., Yannarelli, G.G.: Nitric oxide synthaselike dependent $\mathrm{NO}$ production enhances heme oxygenase up-regulation in ultraviolet-B-irradiated soybean plants. Phytochemistry 71: 1700-1707, 2010.

Scuffi, D., Álvarez, C., Laspina, N., Gotor, C., Lamattina, L., García-Mata, C.: Hydrogen sulfide generated by L-cysteine desulfhydrase acts upstream of nitric oxide to modulate abscisic acid-dependent stomatal closure. - Plant Physiol. 166: 2065-2076, 2014.

Scuffi, D., Lamattina, L., García-Mata, C.: Gasotransmitters and stomatal closure: is there redundancy, concerted action, or both?. - Front. Plant Sci. 7: 277, 2016.

Scuffi, D., Nietzel, T., Di Fino, L.M., Meyer, A.J., Lamattina, L., Schwarzländer, M., Laxalt, A.M. Garcia-Mata, C.: Hydrogen sulfide increases production of NADPH oxidase-dependent hydrogen peroxide and phospholipase D-derived phosphatidic acid in guard cell signaling. - Plant Physiol. 176: 2532-2542, 2018.

Sehrawat, A., Deswal, R.: Sub-proteome S-nitrosylation analysis in Brassica juncea hints at the regulation of Brassicaceae specific as well as other vital metabolic pathway(s) by nitric oxide and suggests post-translational modifications cross- talk. - Nitric Oxide 43: 97-111, 2014.

She, X.P., Song, X.G.: Carbon monoxide-induced stomatal closure involves generation of hydrogen peroxide in Vicia faba guard cells. - J. Integr. Plant Biol. 50: 1539-1548, 2008.

Shekhawat, G.S., Verma, K.: Haem oxygenase (HO): an overlooked enzyme of plant metabolism and defence. - J. exp. Bot. 61: 2255-2270, 2010.

Shi, C., Chen, F., Peng, T., She, X.: Role of cytoplasmic alkalization and nitric oxide in ethylene-induced stomatal closure in Arabidopsis. - Int. J. agr. Biol. 19: 1220-1226, 2017.

Shi, C., Qi, C., Ren, H., Huang, A., Hei, S., She, X.: Ethylene mediates brassinosteroid-induced stomatal closure via $\mathrm{G} \alpha$ protein-activated hydrogen peroxide and nitric oxide production in Arabidopsis. - Plant J. 82: 280-301, 2015a.

Shi, H., Ye, T., Han, N., Bian, H., Liu, X., Chan, Z.: Hydrogen sulfide regulates abiotic stress tolerance and biotic stress resistance in Arabidopsis. - J. integr. Plant Biol. 57: 628-640, 2015b.

Shi, K., Li, X., Zhang, H., Zhang, G., Liu, Y., Zhou, Y., Xia, $X$. ., Chen, Z., Yu, J.: Guard cell hydrogen peroxide and nitric oxide mediate elevated $\mathrm{CO}_{2}$-induced stomatal movement in tomato. - New Phytol. 208: 342-353, $2015 \mathrm{c}$.

Sobahan, M.A., Akter, N., Okuma, E., Uraji, M., Ye, W., Mori, I.C., Nakamura, Y., Murata, Y.: Allyl isothiocyanate induces stomatal closure in Vicia faba. - Biosci. Biotech. Biochem. 79: $1737-1742,2015$

Sokolovski, S., Blatt, M.R.: Nitric oxide block of outwardrectifying $\mathrm{K}^{+}$channels indicates direct control by protein nitrosylation in guard cells. - Plant Physiol. 136: 4275-4284, 2004.

Song, X.G., She, X.P., Zhang, B.: Carbon monoxide-induced stomatal closure in Vicia faba is dependent on nitric oxide synthesis. - Physiol. Plant. 132: 514-525, 2008.

Su, J., Yang, X., He, J., Zhang, Y., Duan, X., Wang, R., Shen, W.: Methyl-coenzyme M reductase-dependent endogenous methane enhances plant tolerance against abiotic stress and alters ABA sensitivity in Arabidopsis thaliana. - Plant mol. Biol. 101: 439-454, 2019.

Sun, L.R., Hao, F.S., Lu, B.S., Ma, L.Y.: AtNOA1 modulates nitric oxide accumulation and stomatal closure induced by salicylic acid in Arabidopsis. - Plant Signal. Behav. 5: 10221024,2010

Takemiya, A., Yamauchi, S., Yano, T., Ariyoshi, C., Shimazaki, K.I.: Identification of a regulatory subunit of protein phosphatase 1 which mediates blue light signaling for stomatal opening. - Plant Cell Physiol. 54: 24-35, 2013.

Tamaoki, M.: The role of phytohormone signaling in ozoneinduced cell death in plants. - Plant Signal. Behav. 3: 166174,2008

Tao, C., Tian, M., Han, Y.: Hydrogen sulfide: A multi-tasking signal molecule in the regulation of oxidative stress responses - J. exp. Bot. 71: 2862-2869, 2020.

Underwood, W., Melotto, M., He, S.Y.: Role of plant stomata in bacterial invasion. - Cell. Microbiol. 9: 1621-1629, 2007.

Uraji, M., Katagiri, T., Okuma, E., Ye, W., Hossain, M.A., Masuda, C., Miura, A., Nakamura, Y., Mori, I.C., Shinozaki, K., Murata, Y.: Cooperative function of PLD $\delta$ and PLD $\alpha 1$ in abscisic acid-induced stomatal closure in Arabidopsis. - Plant Physiol. 159: 450-460, 2012.

Vahisalu, T., Puzõrjova, I., Brosché, M., Valk, E., Lepiku, M., Moldau, H., Pechter, P., Wang, Y.S., Lindgren, O., Salojärvi, J., Loog, M.: Ozone-triggered rapid stomatal response involves the production of reactive oxygen species, and is controlled by SLAC1 and OST1. - Plant J. 62: 442-453, 2010.

Vandelle, E., Delledonne, M.: Peroxynitrite formation and function in plants. - Plant Sci. 181: 534-539, 2011. 
Wang, L., Ma, X., Che, Y., Hou, L., Liu, X., Zhang, W.: Extracellular ATP mediates $\mathrm{H}_{2} \mathrm{~S}$-regulated stomatal movements and guard cell $\mathrm{K}^{+}$current in a $\mathrm{H}_{2} \mathrm{O}_{2}$-dependent manner in Arabidopsis. - Sci. Bull. 60: 419-427, 2015.

Wang, M., Liao, W.: Carbon monoxide as a signaling molecule in plants. - Front. Plant Sci.7: 572, 2016.

Wang, R.: Two's company, three's a crowd: can $\mathrm{H}_{2} \mathrm{~S}$ be the third endogenous gaseous transmitter?. - FASEB J. 16: 1792-1798, 2002.

Wu, L., Wu, H., Chen, L., Zhang, H., Gao, X.: Induction of systemic disease resistance in Nicotiana benthamiana by the cyclodipeptides cyclo (1-Pro-1-Pro) and cyclo (d-Pro-d-Pro). Mol. Plant Pathol. 18: 67-74, 2017.

Xie, Y., Mao, Y., Duan, X., Zhou, H., Lai, D., Zhang, Y., Shen, W.: Arabidopsis HY1-modulated stomatal movement: an integrative hub is functionally associated with ABI4 in dehydration-induced ABA responsiveness. - Plant Physiol. 170: 1699-1713, 2016.

Xie, Y., Mao, Y., Zhang, W., Lai, D., Wang, Q., Shen, W.: Reactive oxygen species-dependent nitric oxide production contributes to hydrogen-promoted stomatal closure in Arabidopsis. Plant Physiol. 165: 759-773, 2014.

Yang, W., Zhang, W., Wang, X.: Post-translational control of
ABA signalling: the roles of protein phosphorylation and ubiquitination. - Plant Biotechnol. J. 15: 4-14, 2017.

Yao, Y., Yang, Y., Li, C., Huang, D., Zhang, J., Wang, C., Li, W., Wang, N., Deng, Y., Liao, W.: Research progress on the functions of gasotransmitters in plant responses to abiotic stresses. - Plants 8: 605, 2019.

Yin, Y., Adachi, Y., Ye, W., Hayashi, M., Nakamura, Y., Kinoshita, T., Murata, Y.: Difference in abscisic acid perception mechanisms between closure induction and opening inhibition of stomata. - Plant Physiol. 163: 600-610, 2013.

Yu, M., Lamattina, L., Spoel, S.H., Loake, G.J.: Nitric oxide function in plant biology: a redox cue in deconvolution. - New Phytol. 202: 1142-1156, 2014.

Zhang, T., Chen, S., Harmon, A.C.: Protein phosphorylation in stomatal movement. - Plant Signal. Behav. 9: e972845, 2014.

Zhang, T.Y., Li, F.C., Fan, C.M., Li, X., Zhang, F.F., He, J.M.: Role and interrelationship of MEK1-MPK6 cascade, hydrogen peroxide and nitric oxide in darkness-induced stomatal closure. - Plant Sci. 262: 190-199, 2017.

Zhao, X., Li, Y.Y., Xiao, H.L., Xu, C.S., Zhang, X.: Nitric oxide blocks blue light-induced $\mathrm{K}^{+}$influx by elevating the cytosolic $\mathrm{Ca}^{2+}$ concentration in Vicia faba L. guard cells. - J. Integr. Plant Biol. 55: 527-536, 2013. 